\title{
Architecture of dwarf shrubs and dwarf subshrubs of the genus of Thymus $L$. and Scutellaria L. (Lamiaceae)
}

\author{
Vera Cheryomushkina, Evgeniya Talovskaya,", and Alexandra Guseva ${ }^{1}$ \\ ${ }^{1}$ Central Siberian Botanical Garden SB RAS, 630090 Novosibirsk, Russia
}

\begin{abstract}
The structure of 24 species of Thymus and 12 species of Scutellaria was studied using the architectural approach. For the first time, an architectural unit was described, it is a branched sympodial axis. The architectural unit consists of sympodial axes $n+1$ order, formation shoots, branching shoots, ephemerous shoots. The wide distribution of species and development of species in contrasting habitat conditions is due to the diversity of sympodial axes and shoots that are part of the architectural unit. Depending on the type of branching and the spatial position of sympodial axes, six modifications of architectural unit were identified. It is established that the structure of mature individuals are formed due to the repetition one of the same modification of architectural unit or a combination different modifications of architectural unit. Each of the variants of the combination determines the type of life form (dwarf shrub or dwarf subshrub) and biomorph (monocentric, dense polycentric, sparse polycentric) and depends on the conditions of the ecotope. The identified modifications of the architectural unit and the variants of their combination determine the strategy for the development of dwarf shrubs and dwarf subshrubs in the development of Northern and Central Asia.
\end{abstract}

The study of the morphological structure of plants and its changes depending on the characteristics of the development of individuals and environmental conditions is one of the promising areas of research in recent decades. Within the framework of this direction, a methodological basis for the description of architectural models and architectural units in plants has been developed [1,2]. Currently, this approach opens up wide prospects for understanding the morphological mechanisms of adaptation of species to different growing conditions, the spatial location of plants, as well as modeling scenarios of environmental impact on plant structure $[3,4,5]$. The study of the architecture of dwarf shrubs and dwarf subshrubs from these positions was practically not carried out $[6,7]$. Dwarf shrubs and dwarf subshrubs are widely represented in the vegetative cover of Northern and Central Asia and are edificators of some types of vegetation. The analysis of architecture will allow us to determine the set of structural and functional features that ensure the growth of dwarf shrubs and dwarf subshrubs in contrasting ecotopes.

\footnotetext{
*Corresponding author: kolegova_e@ mail.ru
} 
The objects of our study are species of the genus Thymus and the genus Scutellaria, which is due to their dominance in different types of communities and growing in ecologically different ecotopes, as well as the predominance of dwarf shrub and dwarf subshrubs life forms in both genus. Our research is aimed at identifying the architectural unit in individuals of Thymus and Scutellaria and its modification options depending on environmental conditions.

\section{Materials and methods}

We analyzed the architecture of 24 species of Thymus and 12 species of Scutellaria distributed in Central and Northern Asia. We applied the ecological-morphological classification by I.G. Serebryakov [8] for identification of life forms Thymus, Scutellaria and the architectural approach for identify architectural units [9,2]. An architectural unit $(\mathrm{AU})$ is the main structural-functional unit of a concrete species containing a full range of all hierarchically subdominant structures and repetitive in the general plant architecture. The characters of AU in each plant species are stable and change quantitatively according to growth conditions [9]. We used 19 characteristics for to identify AU. Characteristics of sympodial axes: the type of branching (basi-, acrosympodial), spatial position (orthotropic, plagiotropic, mixed or orthotropic-plagiotropic), number and structure of formation shoots in the sympodial axis; duration of monopodial growth of formation shoots; length, duration of growth and origin (main, lateral) of the sympodial axis; number of lateral generative, vegetative shoots and sympodial axes of the nth order; number of secondary taproots. Characteristics of shoots: duration of monopodial growth; function (formation shoot, branching shoot, ephemerous shoot); development cycle (complete, incomplete); spatial position (orthotropic, plagiotropic); number of adventitious roots; length of the perennial part of the shoot; origin (axillary or terminal bud); structure (shorted shoot, elongated shoot); number of lateral generative and vegetative shoots).

\section{Results}

It was found that the architecture of dwarf shrubs and dwarf subshrubs of Thymus and Scutellaria had been formed due to the multiple reiteration of the same architectural unit. The architectural unit is a branched sympodial skeletal axis (the sympodial axis $\mathrm{n}$ order). The architectural unit consists of sympodial axes $n+1$ order, formation shoots, branching shoots, ephemerous shoots (Figure). The analysis showed that the architectural unit is unchanged in the representatives of the two genus throughout the Asian part of the range. We have determined the quantitative and qualitative characteristics of sympodial axes and shoots, which vary depending on the conditions of the ecotope.

Modifications of the architectural unit is revealed to depending on the type of branching and the spatial position of sympodial axis. Modifications of architectural unit with basisympodial axes and acrosympodial axes were identified. Modification of architectural unit in the first case is causes for the formation a dwarf subshrub, in the second case - a dwarf shrub. The differentiation of sympodial axes by the spatial position allowed us to distinguish next modifications of architectural unit: orthotropic, plagiotropic, and mixed type. Six modifications of architectural unit were identified (Table). 


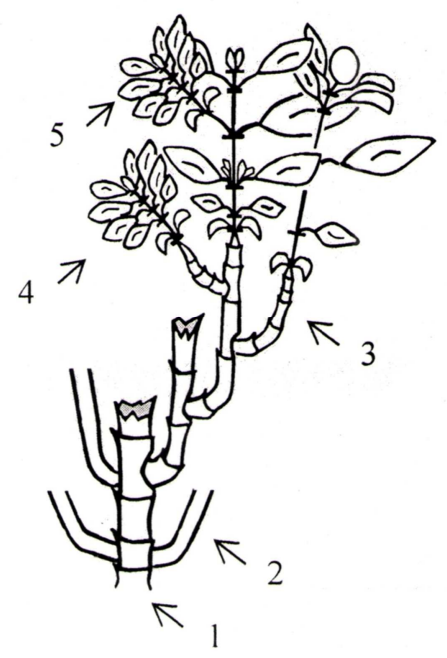

Figure. Architectural unit of Thymus and Scutellaria (1 - sympodial axis n order, 2 - sympodial axis $\mathrm{n}+1$ order, 3 - formation shoot, 4 - branching shoot, 5 - ephemerous shoot).

Table. Diversity of modifications of an architectural unit in the structure of Thymus and Scutellaria individuals

\begin{tabular}{|c|c|c|c|c|c|c|}
\hline $\begin{array}{c}\text { type of } \\
\text { branching of } \\
\text { sympodial } \\
\text { axis }\end{array}$ & \multicolumn{2}{|c|}{$\begin{array}{c}\text { AU with basisympodial axes } \\
\text { (dwarf subshrub) }\end{array}$} & \multicolumn{3}{|c|}{$\begin{array}{c}\text { AUs with acrosympodial axes } \\
\text { (dwarf shrub) }\end{array}$} \\
\hline $\begin{array}{c}\text { spatial } \\
\text { position of } \\
\text { sympodial } \\
\text { axis }\end{array}$ & $\begin{array}{c}\text { orthotropic } \\
\text { AU I }\end{array}$ & $\begin{array}{c}\text { plagiotropic } \\
\text { AU II }\end{array}$ & $\begin{array}{c}\text { mixed } \\
\text { type AU } \\
\text { III }\end{array}$ & $\begin{array}{c}\text { orthotropic } \\
\text { AU IV }\end{array}$ & $\begin{array}{c}\text { plagiotropic } \\
\text { AU V }\end{array}$ & $\begin{array}{c}\text { mixed } \\
\text { type } \\
\text { AU VI }\end{array}$ \\
\hline $\begin{array}{c}\text { modifications } \\
\text { of AU in the } \\
\text { structure of } \\
\text { individual }\end{array}$ & $\bullet$ & AU I & \multicolumn{2}{|c|}{ AU IV } \\
\hline
\end{tabular}

The structure of mature individuals of the species of Thymus and Scutellaria is constructed by repetition one of the same modification of architectural unit or a combination different modifications of architectural unit. Three variations of the combination of modifications of architectural unit in the structure of dwarf shrubs and four variations in the structure of dwarf subshrubs were found. For example, in dwarf shrubs ( $T$. baicalensis Serg., T. mongolicus (Ronn.) Ronn.) and dwarf subshrubs (T. extremus Klok., T. marschallianus Willd., T. roseus Schipz., S. supina L., S. grandiflora Sims) that develop in petrophytic steppe communities along mountain tops, the structure is formed by repeating only orthotropic AU, forming a monocentric type of biomorph [10, 11, 12]. When structure of bush is repeat AU II or AU II and AU III (AU V and AU VI), sparse polycentric type of biomorph is formed, the individual is a clump or clone consisting of single-aged partial bushes (T. roseus, T. pavlovii Serg., T. iljinii Klok. et Shost., T. krylovii Byczennikova) [13]. The sparse polycentric type of biomorph is rarely observed, mainly in forest communities with moss cover, in sandy steppes with a fixed substrate, and in blackened alpine meadows. The combination of orthotropic and plagiotropic modifications of architectural unit and the formation of a dense polycentric biomorph is most typical for the studied species. Such a 
structure of Thymus was found in different plant communities located on the slopes of mountains or on the foothills (T. altaicus Klok. et Shost., T. brevipetiolatus Čáp, T. elegans Serg., T. jenisseensis Iljin., T. indigirkensis Karav., T. minussinensis Serg., T. proximus Serg., T. mongolicus (Ronn.) Ronn., T. sibiricus (Serg.) Klok. et Schost. and others), and of Scutellaria on a sandy substrate and large-scale scree (S. przewalskii Juz., S. phyllostachya Juz., S. sieversii Bunge) [12, 14, 15, 16].

As our studies have shown, in the same coenopopulation, all individuals show mainly the same modifications of architectural unit. We described isolated cases when individuals at different loci of the same coenopopulation have different modifications of architectural unit. This is typical for species at the border of their ranges or in non-typical conditions. Thus, in the coenopopulation of $T$. jenisseensis, studied in the upper border of the forest belt in the Barlyk River valley on the Tsagan-Shibetu ridge (Tuva), different modifications of architectural unit and, as a result, different life forms were revealed in individuals. In the lowering of the relief at the site of the temporary watercourse, the structure of individuals is formed due to AU I and AU II with basisimpodial axes (dwarf subshrub); around the edges of the temporary watercourse, the structure of individuals is formed due to AU IV and AU V with acrosympodial axes (dwarf shrub) [17].

Changes in the other characteristics of the sympodial axis and shoots (number, structure, length, branching, and place of formation) do not lead to modifications of the architectural unit, but reflect its polyvariance. For example, morphological polyvariance of $T$. petraeus is associated with a change in the set of elements of an architectural unit. Ephemerous shoots always is absent in the structure of architectural unit, when species are develop on the tops of hills. In the condition of sandy steppes, the structure of individuals is simplified due to the absence of orthotropic modification of architectural unit. Depending on the presence of a free substrate, the rocky cover, and the total projective grass cover, there is a dimensional (a diversity of lengths of sympodial axes $n$ order and the number of sympodial axes $n+1$ order) and dynamic (the duration of the monopodial growth of the formation shoots) polyvariance [18].

Thus, the structure of the dwarf shrubs and dwarf subshrubs of Thymus and Scutellaria is formed due to the repetition different modifications of architectural unit. The modifications of architectural unit manifests itself depending on the conditions of the ecotope and determines the strategy for the development of dwarf shrubs and dwarf subshrubs in Northern and Central Asia.

This work was supported by the Russian Foundation for Basic Research, project № 1804-00621, and made within the framework of the state task of the Central Siberian Botanical Garden, Siberian Branch, Russian Academy of Sciences, № AAAA-A21121011290026-9.

\section{References}

1. F. Hallé, R. A. A. Oldeman, Essai sur l'architecture et la dynamique de croissance des arbres tropicaux (Masson, Paris, 1970)

2. D. Barthélémy, Y. Caraglio, Annals of botany, 99(3) (2007)

3. Y. Guo, T. Fourcaud, M. Jaeger, X. Zhang, B. Li, Annals of botany, 107 (2011)

4. T. Charles-Dominique, C. Edelin, J. Brisson, A. Bouchard, Botany, 90 (2012)

5. M. V. Kostina, N. S. Barabanshikova, G. V. Bityugova, O. I. Yasinskaya, A. M. Dubach, Contemp. Probl. Ecol., 8(5) (2015)

6. T. Navarro, V. Pascual, B. Cabezudo, C. Alados, Candollea, 64 (2009) 
7. S. Gambino, F. Ratto, A. Bartoli, Boletin de Sociedad Argentina de Botanica, 51(4) (2016)

8. I. G. Serebrjakov, Ecological plant morphology (AN SSSR, Moscow, 1962)

9. Y. Caraglio, C. Edelin, Bulletin de la Société Botanique de France, Lettres botaniques, 137(4-5) (1990)

10. V. A. Cheryomushkina, A. A. Guseva, Contemp. Probl. Ecol., 8(5) (2015)

11. V. A. Cheryomushkina, A. A. Guseva, Plant resources, 53(3) (2017)

12. V. Cheryomushkina, E. Talovskaya, A. Astashenkov, Biharean biologist, 13(2) (2019)

13. E. B. Talovskaya, V. A. Cheryomushkina, G. R. Denisova, Contemp. Probl. Ecol., 11(6) (2018)

14. A. A. Guseva, Ontomorphogenesis of different life forms Scutellaria przewalskii Juz. (Moscow, 2019)

15. A. A. Guseva, V. A. Cheryomushkina, Plant Life of Asian Russia, 3(35) (2019)

16. V. Cheryomushkina, E. Talovskaya, Bot. J., 104(3) (2019)

17. E. B. Talovskaya, V. A. Cheryomushkina, I. N. Barsukova, Contemp. Probl. Ecol., 3(1) (2020)

18. E. Talovskaya, I. Barsukova, N. Kurochkina, BIO Web Conf., 24 (2020) 